\title{
Using rates of gravestone decay to reconstruct atmospheric sulphur dioxide levels
}

Rob Inkpen, ${ }^{1}$ Howard D. Mooers ${ }^{2}$, and Michael J. Carlson ${ }^{2}$

1 Department of Geography, University of Portsmouth, Buckingham Building, Lion Terrace Portsmouth, Hampshire PO1 3HE

2 Department of Earth and Environmental Sciences, University of Minnesota Duluth, Duluth, MN 58812, USA

\begin{abstract}
Decay losses from marble gravestones spanning the last 130 years were measured using the lead lettering index (LLI). The relationship between decay loss and gravestone age can be described using a power function of the form decay loss $=\mathrm{a}(\mathrm{age})^{\mathrm{b}}$. For locations where decay is likely to have been dominated by 'normal' rainfall the value of $\mathrm{b}$ tends to 1 , whilst for locations where decay losses were higher in the past $b$ tends towards a value of 2 . Using Lipfert's dose-response function it is possible to postdict atmospheric sulphur dioxide concentrations using rainfall records and yearly decay rates derived from the power functions. Comparing the derived historic atmospheric sulphur dioxide concentrations between locations, the highest levels are found in the industrial location of Swansea compared to the relatively high historic levels found in urban area such as Oxford, Birmingham and Portsmouth. Suburban or rural locations tend to have very low concentrations.
\end{abstract}

Keywords: Gravestone decay, atmospheric pollution, reconstruction, sulphur dioxide 


\section{Introduction}

Estimation of sulphur dioxide concentration in urban atmospheres in the UK before the 1960s depend on proxies, such as industrial and commercial activity (e.g. Inkpen, 1989), coal records or cathedral repair records (e.g. Brimblecombe, 1977, Viles, 1996, Inkpen, 1999). Reconstructing past sulphur dioxide levels provides important information on the nature of the decay environment experienced by historic buildings and their responses to these conditions. In particular the potential presence of cumulative and thresholds values for the impact of atmospheric pollutants for stone decay could be analysed looking at historic records of building repair within quantified historic atmospheric pollution environments. Historic pollution levels also provide an important environmental context for understanding the efficacy of environmental regulation, and public health related issues (Spix et al. 1993; Greenstone, 2004); an understanding that can be used to predict the potential impact of increasing urbanisation.

Likewise, other techniques of environmental reconstruction such as dendrochronology, can benefit from information about atmospheric pollution conditions under which tree growth occurred as variations in these can affect growth and therefore the interpretation of past climates (Martinelli, 2004, Muzika et al., 2004, Stravinskiene et al., 2013).

Recently Bonazza et al. (2009) and Brimblecombe and Grossi (2008) used the Lipfert doseresponse functions, derived under contemporary conditions, to postdict past decay rates. Inkpen et al. (2012) used these dose-response functions to compare modelled rates with measured rates. Inkpen (2013) rearranged the Lipfert dose-response function (Lipfert, 1989) to determine past sulphur dioxide from the decay rate of marble gravestones in three urban locations. The integrative rate method employed, however, was at a relatively low decadal resolution and was limited by the number of samples in each decade, the spread of the data and sensitivity to individual extreme values as well as being time consuming to apply. 
Investigations have shown that measurement of surface recession of lead-lettered Carrara marble gravestones provide a robust and repeatable measure of acid deposition (e.g. Meierding, 1981; Cooke et al., 1995; Thornbush and Thornbush, 2013; Mooers et al., 2016).

Carrara marble tends to have low porosity and are predominantly composed of calcium carbonate. It decays mainly through dissolution from natural rainfall (weak carbonic acid) and from wet and dry acid deposition, mainly of sulphuric and nitric acids, in polluted environments. The flux of acid to the surface of the gravestone is related to atmospheric concentrations and the deposition velocity (e.g. Behlen et al., 2008). As the gravestone ages, however, crack development may make it susceptible to decay by physical agents such as frost and salts. Surface recession on individual stones has been shown to be very consistent; however, variability among stones can be large. Despite this variability, Mooers et al. (2016) show that conversion of average surface recession rates to acid deposition correspond closely with measured acid deposition across Europe determine by Whelpdale et al., 1997.

This paper outlines a different method for deriving past atmospheric sulphur dioxide levels from decay losses but also provides a clearer indication of the nature of the limitations and sources of error in such reconstructions.

\section{Limitations of the Integrative Rate Method}

The method used by Inkpen (2013) can produce negative rates of decay and negative concentrations of sulphur dioxide for some time periods. The method is an integrative rate method as it used the raw data on decay losses over time and incrementally subtracted earlier losses from later losses for decades to derive decadal decay rates. The application of the Lipfert equation to decay data for Lodge Hill Cemetery (Selly Oak) is illustrated in Table 1 and Figures 1A and B. As 
well as negative decay rates, applying a moving average to the data as in Figure 1B, highlights the presence of negative slope. Negative slopes indicate accretion of material to the gravestone which is not possible and reflect an artefact of the calculation method. The peak-to-peak periodicity of the oscillation from positive to negative decay rates are 22 years for the integrative rate and 16 years for the 10-point moving average (Mooers et al., 2016). The periodicity is similar to the average difference between successive inscriptions on gravestones in this cemetery which is 16.7 years. Mooers et al. (2016) document a large natural variability in the erodibility of Carrera marble gravestones, with 'soft' stones decaying up to three times faster than 'hard' stones. Time periods where 'hard' gravestones dominate measured decay losses would be expected to have lower decay rates than where 'soft' gravestones dominate measured decay losses. The wide range of stone variability in the data set may be a contributing factor to the limitations of using the integrative method for calculating decadal decay rates and so decadal concentrations of atmospheric sulphur dioxide. This limitation is likely to be severe when there are relatively few data points to calculate decay rates in each decade and when 'hard' and 'soft' gravestones cluster in time. The alternative method proposed below makes use of the characteristics of the whole data set for each location and so limits the impact of variability in stone 'hardness' on derived decay rates.

\section{Modelling Gravestone Decay}

The data sets used in this analysis are those used by Cooke et al. (1995) for Swansea and Portsmouth, by Inkpen and Jackson (2000) for Oxford and by Mooers et al. (2016) for graveyards in the West Midlands (Jewellery Quarter in central Birmingham with the sites of Warstone and Key Hill, West Bromwich, Kings Heath, Selly Oak and South Yardley). These locations were selected as they illustrate both the potential of this technique as well as the problems of using such datasets for reconstructing past pollution environments (see Figures $2 \mathrm{~A}$ and $\mathrm{B}$ for site locations). In all cases the data were collected using the lead lettering index (LLI) method (Cooke et al., 1995, Inkpen and 
Jackson, 2000). This method assumes that since the erection of the gravestone, the original polished surface of the Carrara marble has been lost whilst the lead lettering, originally flush with the marble surface, has not changed. The lead lettering becomes a reference surface from which the height of loss of marble can be measured using a set of callipers. The letters and position on the letters measured is standardised as in Cooke et al. (1995) so that at least 10 height losses for each gravestone are measured. Dividing the heights lost by the age of the gravestone, the average decay rate can be calculated for each gravestone. No rural data set was included in the analysis as these locations rarely have enough marble gravestones to permit the calculation of a reasonable statistical relationship. The limited population size of rural areas as well as the limited economic resources of this population may partly explain this lack of appropriate gravestones for analysis. Future research will focus on obtaining such datasets to provide a baseline for comparison to the relationships observed in urban and suburban location.

The relationship between gravestone age and amount of decay, as represented by height losses, has been modelled in the past using linear regression most recently by Mooers et al. (2106). The relatively high $\mathrm{r}^{2}$ values, reflecting the amount of variation in the data explained by the linear regression, suggested that there was little additional explanatory value in fitting a more complex curve to the datasets. The constant gradient of the curve means that there is no variation in decay rates over time whereas it would be expected that decay rates would be higher in more polluted environments. Detailed examination of the datasets suggests that there is an improvement in the explanatory value, albeit slight in some cases, if a power function is fitted to the datasets (Table 2 and an illustration for Oxford in Figure 3) for every location except West Bromwich.

Using a power function of the form:

$\mathrm{y}=\mathrm{ax} \mathrm{x}^{\mathrm{b}}$ (Eqn 1) 
to describe the relationship between age of gravestone and amount of loss does produce a change in decay rates over time. The power functions b vary in value between 1 and 2 with two distinct groupings of values, where $\mathrm{b}$ is close to 2 and where $\mathrm{b}$ is closer to 1 . These groupings represent sites where changes in surface losses over time are increasingly described by a near quadratic relationship and sites where changes in surface losses are closer to linear over time. This distinction is an important one for reconstruction as discussed below.

It is important to bear in mind that the power relationship between gravestone age and amount of loss does not necessarily identify atmospheric pollution as the cause of the relationship. The power function represents the integrative effect on decay of all contributing agents of decay including rainfall and temperature variations over time, which may co-vary over time. If rainfall amounts were higher in the past then their impact upon decay could have been combined with the impact of higher levels of atmospheric pollution and would produce higher amounts of surface loss. Figure 4 illustrates the relationship between rainfall amount and date for four sites for the time period of gravestone loss at each location. There appears to be no clear relationship between annual average rainfall and time. The decay losses represent the cumulative losses so it is the relationship to cumulative rainfall that needs to be considered rather than the trend in individual annual rainfall. Cumulative rainfall increases in a linear rather than polynomial manner over time all location with $r^{2}$ values of 0.99 or greater. This implies that the polynomial relationship between age and amount of loss is not related to cumulative rainfall.

The use of Lipfert's dose-response function enables the relative contribution to decay of yearly rainfall amount to be quantified. Within Lipfert's model the decay losses attributed to rainfall amount alone are viewed as the 'karstic' component of decay losses. 'Karstic' in this context refers to the dissolution of the marble surface due to reactions 'normal' rainfall of weak carbonic acid with a $\mathrm{pH}$ of 5.6. This convention is followed in this paper. Average temperature has changed over time 
usually increasing slightly over the time periods of exposure of gravestones as illustrated in Figure 5 for Oxford. The potential impact of this change on the decay rates of gravestones will be discussed below but it can not be modelled using the Lipfert dose-response function.

\section{Converting Decay Losses to Atmospheric Sulphur Dioxide Levels}

Decay losses were derived from the power functions across the time period for which gravestone data were measured at each site with differences between years representing the decay rate for that year. Inkpen's (2013) rearranged version of Lipfert's dose-response model, was used to postdict sulphur dioxide levels. The Lipfert equation is:

$\mathrm{ER}=(18.8 \mathrm{R})+\left(0.016\left[\mathrm{H}^{+}\right]\right) \mathrm{R}+\left(0.18\left(0.38 \mathrm{SO}_{2}\right)+\left(0.32 \mathrm{HNO}_{3}\right) \quad(\mathrm{Eqn} 2)\right.$

Where ER represents the decay in $\mu \mathrm{m}$ per year, $\mathrm{R}$ is the annual rainfall in metres, $\mathrm{H}^{+}$is the hydrogen ion concentration in $\mu \mathrm{mol} 1^{-1}$ and 0.38 and 0.32 represent the deposition velocities of $\mathrm{SO}_{2}$ and $\mathrm{HNO}_{3}$ respectively in $\mathrm{cm} \mathrm{s}^{-1} . \mathrm{SO}_{2}$ and $\mathrm{HNO}_{3}$ are expressed in $\mu \mathrm{g} \mathrm{m}^{-3}$. Using Brimblecombe and Grossi (2008) as a basis for assessing the relative importance of the different equation components the following alterations were made. The $\mathrm{HNO}_{3}$ term was excluded as Brimblceombe and Grossi estimated that, at best, it contributes only $10 \%$ to the decay rates over the time period for which gravestone measurements are available in this study. The $\mathrm{H}^{+}$concentration is also excluded as their analysis suggests acid rain is contributes less than $10 \%$ to decay rates even in periods of high atmospheric pollution. This does mean, however, that all decay attributable to sulphur dioxide will be as dry deposition in the modified equation possibly resulting in an overestimation of sulphur dioxide levels in periods of high pollution as the contribution of wet deposition is not considered. The constant of 18.8 represents the solubility of calcareous stone in clean rainfall, i.e. rainfall with a $\mathrm{pH}$ of 5.6. This constant is modified using the research of Baedecker and Reddy (1993) that 
compared the dissolution of limestone and marble under conditions of varying $\mathrm{pH}$. The ratio between the intercept values for limestone and marble is 1.9375 as used in the modified equation below and in Inkpen (2013). This correction factor is required as dissolution may vary with the porosity of the stone as well as other physical characteristics as Lipfert himself noted.

The modified equation is:

$\mathrm{SO}_{2}=(\mathrm{ER}-(18.8 / 1.9375) \mathrm{R}) / 0.0684$

$\mathrm{SO}_{2}$ expressed in $\mu \mathrm{g} \mathrm{m}^{-3}$.

Although there are other, more recent functions that link environmental parameters to stone loss over the short term such as Kurcera, 2005, Kucera et al., 2007 and MULTI-ASSESS, 2007, each of these requires the use of parameters, such as relative humidity conditions, that are difficult to find historically. The Lipfert equation requires historic rainfall records for its calculation and so it is relatively easy to find consistent and accurate historic sources for this environmental data over the period of gravestone measurement.

The dose response equation derived by Tidblad et al. (2001) was considered but the range of sulphur dioxide concentrations over which the data were modelled, as noted by Tidblad et al., was between 1 and $83 \mu \mathrm{g} \mathrm{m}^{-3}$, a range likely to be exceeded in the historic period under investigation. A trial analysis of the rearranged Tidblad et al. (2001) equation using the Oxford decay data produced consistently and substantially lower sulphur dioxide levels compared to the Lipfert equation, usually less than $50 \%$ of the derived values. Given the estimated sulphur dioxide levels from Brimblecombe and Grossi (2008) substantially exceeded those produced by the application of the Tidblad et al. equation to historic data; it was decide to use the rearranged Lipfert equation alone for reconstruction purposes. 
Rainfall data for was sourced from the Meteorological Office's archives. with Birmingham (Edgbaston site) rainfall records being used for all the West midlands sites being used in the modified equation as this site was one of the few continuously operating throughout the period for which gravestone measurements were available. It should be noted, however, as in Brimblecombe and Grossi (2008) and Grossi et al. (2008), that the Lipfert dose-response function has a relatively large karstic component. This means that the equation may tend to overestimate the contribution of 'natural' rainfall to decay.

Applying equation 3 to the datasets enables past atmospheric sulphur dioxide levels to be calculated as in Figure 6 for Oxford, Swansea, the Jewellery Quarters sites (Warstone and Key Hill), Portsmouth and for West Bromwich. Figure 7 illustrates the relationships between derived sulphur dioxide levels and date for Kings Heath, Selly Oak and South Yardley. Rainfall between the three meteorological stations is highly correlated for the time periods for which they overlap (statistically significant at the $\alpha=0.01$ level). There are statistically significant negative relationships (at $\alpha=0.05$ ) between derived sulphur dioxide levels and rainfall amounts at each site except for Swansea that shows no statistically significant relationship. This suggests that as rainfall amount increases sulphur dioxide levels decrease, which may reflect the high contribution of the karstic aspect of the Lipfert function. This will be relatively large in years with high rainfall and so will decrease the relative contribution of dry deposition to the decay of the stone. Between sites there is a high positive correlation between sulphur dioxide levels over time. Given the value of the power function used to model the data at each site increases over time this correlation is to be expected.

Atmospheric sulphur dioxide concentrations at the industrial location of Swansea are higher than concentrations for the urban locations of Oxford, Portsmouth and central Birmingham. The difference persists into the 1960 s even as all these locations experience a decline in concentrations. Noticeably, the curves for the urban sites tend to have similar concentrations as well as a similar 
pattern of decline. This suggests that urban concentrations of atmospheric sulphur dioxide were historically similar at least with respect to their reaction with marble and so in their expression as decay losses. Locations such as Selly Oak, Kings Heath and South Yardley have lower sulphur dioxide levels as reflected in the decay of the marble. The lower historic decay losses for these locations imply they that sulphur dioxide has not been an active agent of decay in the past. The implied domination of decay loss by karstic processes is reflected in no historic decline in sulphur dioxide concentrations being identifiable in these data.

\section{Potentials and Limitations of Reconstructions}

The potential of this method of reconstructing historic atmospheric sulphur dioxide concentrations relies upon the extension over decades of the yearly relationship identified by Lipfert between rainfall, decay and sulphur dioxide levels over a study period of less than a decade. Lipfert's original study combined information from previous short-term research from a number of different locations to derive a multiple regression model of the relationships above. There is no direct test of the stability of the identified relationships over a longer timescale. The relationships might not be stable if non-linear effects over time occur as, for example, a protective surface layer of weathered material builds up or, as is the case with polished marble, initial decay rates are retarded by a polished surface (Klein, 1984). Similarly, the potential for high concentration of sulphur dioxide to react less with the stone as a surface film of moisture decreases in $\mathrm{pH}$ (Behlen et al. 2008) could also alter the nature of the relationships. This analysis has to assume that any such alterations do not impact upon the overall pattern of change over time.

Unlike the use of proxies records mentioned above, decay rates reflect the direct impact of sulphur dioxide upon an artefact in the environment. This means that decay rates reflect both the concentrations of sulphur dioxide and their impact from an empirically derived data source 
concurrent with the atmospheric pollution. Provided standard measuring techniques are used, modelling the relationship between decay rates and environmental factors can be refined as more gravestones can be measured and added to the analysis at a site. The two Jewellery Quarter data sets do, however, illustrate that caution needs to be exercised in this. Despite being very close to each other the two follow different power functions and postdict different concentrations of atmospheric sulphur dioxide, although they both still postdict higher pollution levels in the past. The Key Hill cemetery, which has the smaller power function, has a continuous canopy of trees whereas the Warstone cemetery does not. The tree canopy will neutralize a considerable portion of acid deposition, particularly dry deposition, and so reduce decay losses. Mooers and Massman (in review) document a 50\% decrease in stone decay at Key Hill. This means that a detailed understanding of the context of each cemetery is required to interpret the decay losses measured. Consideration of the potential impact of such site-specific variations in micro-environmental on magnifying differences between decay locations is important to the ability to transfer and up-scale the relationships identified in this paper. If site-specific factors result in high levels of variance in decay as gravestones age then the general trend and magnitude of pollution levels may be discernible from the decay rates of gravestones at a specific location but the absolute values of pollution need to be treated with more caution.

The relationship between decay and temperature is a problematic one. As noted above, annual average temperature has varied though time, but if it is assumed that each gravestone has reacted to the cumulative impact of temperature over time then it may be more appropriate to consider an indicator that represents this cumulative impact over the time period such as average temperature over this time period. Significantly, calcium carbonate solubility increases with decreasing temperature so the lower temperatures in the past would be associated with higher solubility of the gravestone in 'normal' rainfall. Average cumulative temperature has declined in a linear manner over the period of exposure of the gravestones at all locations as Figure 8 illustrates for Oxford at 
the same time as decay losses have declined. Over this time period there is no difference in the $\mathrm{r}^{2}$ value of a linear fit and a power fit to the data (both 0.95) implying that modelling the relationship between date and average cumulative temperature by a linear regression is an appropriate means of describing the relationship between average cumulative temperature and date. This suggests that the higher decay losses for older gravestones may not be attributable to lower temperatures in the past. It is also worth noting that the difference between the average temperature in 1893 and 1954, the period of the decay data for Oxford, is only $0.16^{\circ} \mathrm{C}$ suggesting that any effect from increased solubility on decay losses would be relatively minor.

The use of the power function has the advantage of identifying decay data sets dominated by karstic decay processes and those that are affected more by other decay processes. For locations where the relationship described by the power function has $\mathrm{a} b$ value close to 1 , then it is likely that these locations will be dominated by karstic decay processes. There is no change in decay rate over time as natural rainfall is likely to be the primary control on the magnitude of decay losses. This does not mean that locations cannot have high decay rates, only that these decay rates will not vary greater over time so the amount of decay loss will follow a linear trend. High decay rates but linear losses over time may reflect differences in the amount of rainfall reaching the surface of gravestones in different locations that have persisted over time. Variability in rainfall amount or in tree cover between locations could be a contributing factor to differences in decay rates but will only produce changes in these rates over time if the magnitude of their input has changed historically. A linear trend also implies that if acid deposition did occur in the past it was not at a magnitude sufficient to cause persistently higher decay losses that would be described by a power function. Importantly, as decay rates are relatively constant over time it suggests that there is no factor that was higher in the past to produce higher decay losses that would produce higher decay rates. The linear or near linear relationship reflects the activity of such a congruent process (Colman, 1981). Where the b value approaches 2 then there is a change in the rate of decay over time which suggests higher 
decay rates in the past and so points to the influence of an environmental factor that had a greater impact on decay loss in the past.

For older gravestones there is considerable variation of decay loss with age as noted in Cooke et al. (1995), meaning that there is a wider variation of decay loss about the trend-line described by the power function. Decay losses from older gravestones at some locations also show a clear breakdown of increasing decay losses with age, reversing the relationship in some cases. This could reflect the increased differentiation in decay losses of initially small differences in factors such as variations in stone properties and exposure. Complex feedbacks can emerge in the decay system as the gravestones age resulting, for example, in more surface area being exposed to decay agents as the surface roughens, increasing loss from dissolutional processes. It may mean that at some point in time, the decay losses from the gravestone are dominated by the increase in surface area exposed to decay agents rather solely the environmental conditions - the nature of the entity being studied, the gravestone, has changed so much in character that effectively it is not the same entity as it was at the beginning of the research. In this case the application of the statistical methods identified to the decay data would be inappropriate.

However, Mooers et al. (2016) showed that for the period of about 1930 to 1960 rates of decay on individual stones was essentially linear suggesting that changing surface conditions on stones may not lead to increasing weathering rate (a large number of the stones measured in their investigation had at least three inscriptions per stone).

It has been assumed that the properties of the Carrara marble used in gravestones do not change significantly over the measurement period. If older gravestone were more resistant then it would have lower decay losses relative to the younger gravestones, although Mooers et al. (2016) did consider this factor and found no change in resistance. Even if there were a general change in properties, however, this would not explain the increasing spread of decay rates with age. 
Both the spread of decay losses and the breakdown of a simple age/loss relationship may reflect an inherent limitation of the measurement technique. In some cases, as the marble surface around the lead lettering is lost, the lettering becomes loose and peels away from the surface until it falls off. The large differences in measurements from older gravestones may reflect this movement away from the surface of the lettering as well as placing an upper limit on the decay loss measurable; the upper measurable limit being defined as the time when the lead lettering comes out of the stone. The upper limit may vary between locations, however, depending on how deeply and securely the original lettering was embedded. This means that no single limiting value can be set as to how much decay will result in lead lettering being lost from a gravestone, indeed it may be that lead lettering can survive if it is securely fastened into the gravestone and rapid decay produces a pedestal of marble around the lettering as observed in Swansea. The possibility of an upper limit should, however, means that caution is needed in interpreting decay rates for the latter part of the nineteenth century.

\section{Conclusions}

Marble gravestones with lead lettering are amendable to consistent and standardized measurement of decay loss using the lead lettering index (LLI). The relationship between decay loss and gravestone age can be modelled relatively well using a linear regression or a power function. Where the $\mathrm{b}$ value in the power function describing the relationship at a location is close to 1 , then decay at that location is likely to have been dominated by karstic processes throughout the period of measurement. For locations where the $\mathrm{b}$ value approaches 2 then this implies that other decay processes were more active in the past and produced higher decay losses. In this research, it is assumed that sulphur dioxide is the key variable that was found at higher concentrations in the past and so is the cause of higher decay losses. 
Using a rearranged and modified version of Lipfert's (1989) doss-response function it is possible to postdict concentrations of atmospheric sulphur dioxide. Reconstruction of these levels from decay rates can be used to compare past atmospheric pollution between locations. Initial analysis highlights the difference between pollution levels at the industrial location of Swansea and levels found in urban areas such as Oxford, Birmingham and Portsmouth. More suburban and rural locations tend to have much lower sulphur dioxide levels as the relationship between decay loss and gravestone age tends towards a linear relationship implying natural rainfall is the key variable in determining decay rates throughout the measurement period. Interpretation of the derived sulphur dioxide levels needs to be interpreted with caution, however. The concentrations may provide an indicator of relative levels of atmospheric pollution between locations but potential issues with the measurement technique and with the underlying assumptions of the method as well as a lack of alternative methods for postdicting sulphur dioxide concentrations and that triangulation of the results is not possible.

\section{Acknowledgements}

The authors would like to acknowledge the help of numerous individuals who helped with data collection in the Birmingham area and subsequent data analysis, specifically Avery R Cota-Guertin, Ron R Regal, Tony R Sames, Amanda J Dekan, and Linnea M Henkels. The authors would also like to thank three anonymous reviewers for their constructive comments.

\section{References}

Baedecker, P.A. and Reddy, M.M. 1993. The erosion of carbonate stone by acid rain. Journal of Chemical Education, 70, 104-108. 
Balestrini, R., Arisci, S., Brizzio, M. C., Mosello, R., Rogora, M., \& Tagliaferri, A.2007. Dry deposition of particles and canopy exchange: Comparison of wet, bulk and throughfall deposition at five forest sites in Italy. Atmospheric Environment 41, 745-756.

Behlen, A., Steiger, M. and Dannecker, W. 2008. Deposition of sulfur dioxide to building stones: the influence of the ambient concentration on the deposition velocity. Environmental Geology, 56, 596-603.

Bonazza, A., Messina, P., Sabbioni, C., Grossi, C.M. and Brimblecombe, P. 2009. Mapping the impact of climate change on surface recession of carbonate buildings in Europe. Science of the Total Environment, 407, 2039-2050.

Brimblecombe, P. 1977. London air pollution, 1500-1900. Atmospheric Environment, 11, 11571162.

Brimblecombe, P. and Grossi, C.M. 2008. Millennium-long recession of limestone facades in London. Environmental Geology, 56, 463-471.

Colman, S. 1981. Rock-weathering rates as a function of time. Quaternary Research, 15, 250-264.

Cooke, R.U., Inkpen, R.J. and Wiggs, G.F.S. 1995. Using gravestones to assess changing rates of weathering in the United Kingdom. Earth Surface Processes and Landforms, 6, 531-546. 
Draaijers, G., Erisman, J., Van Leeuwen, N., Römer, F., Te Winkel, B., Veltkamp, A., et al. 1997. The impact of canopy exchange on differences observed between atmospheric deposition and throughfall fluxes. Atmospheric Environment 31(3), 387-397.

Greenstone, M. 2004. Did the Clean Air Acts cause the remarkable decline in sulfur dioxide concentrations? Journal of Environmental and Economics and Management, 47, 585-611.

Grossi, C.M., Bonazza, A, Brimblecombe, P., Harris, I. and Sabbioni, C. 2008. Predicting twentyfirst century recession of architectural limestone in European cities. Environmental Geology, 56, $455-461$.

Inkpen, R.J. 1989. Stone decay and atmospheric pollution in a transect across southern Britain. Unpublished PhD thesis, University of London.

Inkpen, R.J. 1999. Atmospheric pollution and stone degradation in nineteenth century Exeter. Environment and History, 5, 209-220.

Inkpen, R.J. 2103. Reconstructing past atmospheric pollution levels using gravestone erosion rates. Area, 45, 321-329.

Inkpen, R.J. and Jackson, J. 2000. Contrasting weathering rates in coastal, urban and rural areas in southern Britain: preliminary investigations using gravestones. Earth Surface Processes and Landforms, 25, 229-238. 
Inkpen, R.J., Viles, H.A., Moses, C. and Baily, B. 2012. Modelling the impact of changing atmospheric pollution levels on limestone erosion rates in central London, 1980-2010. Atmospheric Environment, 61, 476-481.

Klien, M. 1984. Weathering rates of tombstones measured in Haifa, Israel. Zeitschrift fur Geomorphologie, NF28, 105-111.

Kucera, V. 2005. Model for mulitpollutant impact and assessment of threshold levels for cultural heritage. Swedish Corrosion Institute, Stockholm.

Kucera, V., Tidblad, J., Kreislova, K., Knotkova, D., Faller, M. and Reiss, D. 2007. UN/ECE ICP materials does-response functions for the multi-pollutant situation. In Brimblecombe, P., Hara, H., Houle, D. and Novak, M. (eds.), Acid rain - deposition to recovery. Springer, Dordrecht, 247-258.

Lipfert, F.W. 1989. Atmospheric damage to calcareous stones: comparison and reconciliation of recent experimental findings. Atmospheric Environment, 23, 415-429.

MULTI-ASSESS, 2007. Model for multi-pollutant impact and assessment of threshold levels for cultural heritage. Deliverable 02 (http://www.corr-institute.se/MULTI-ASSESS) accessed 1 August 2015

Martinelli, N. 2004. Climate from dendrochronology: latest developments and results. Global and Planetary Change, 40, 2129-139.

Meierding, T.C. 1981. Marble tombstone weathering rates: A transect of the United States. Physical Geography, 2, 1-18. 
Mooers, H.D., Cota-Guertin, A.R., Regal, R.R., Sames, T.R., Dekan, A.J and Henlels, L.M. 2016. A 120 year record of the spatial and temporal distribution of gravestone decay and acid deposition, West Midlands, UK. Atmospheric Environment, 127, 139-154.

Mooers, H.D. and Massman, W.J. (in review). Gravestone decay and the determination of deciduous bulk canopy resistance to acid deposition. Science of the Total Environment.

Muzika, R.M., Guyette, R.P., Zielonka, T. and Liebhold, A.M. 2004. The influence of $\mathrm{O}_{3}, \mathrm{NO}_{2}$ and $\mathrm{SO}_{2}$ on growth of Picea abies and Fagus sylvatica in the Carpathian Mountains. Environmental Pollution, 130, 65-71.

Neal, C. 2002. Interception and attenuation of atmospheric pollution in a lowland ash forested site, old pond close, Northampton shire, UK. Science of the Total Environment, 282, 99-119.

Schaefer, D.A., Conklin, P., and Knoerr, K. 1992. Atmospheric deposition of acid. In: Johnson, D.W. and Lindberg, S.E., Eds., Atmospheric Deposition and Forest Nutrient Cycling. SpringerVerlag, New York, pp. 427-444.

Spik, C., Heinrich, J., Dockery, D., Schwartz, J., Volksch, G., Schwinkowski, K., Coolen, C. and Wichmann, H.E. 1993. Air pollution and daily mortality in Erfurt, east Germany, 1980-1989. Environmental Health Perspectives, 101, 518-526.

Thornbush, M.J. and Thornbush, S.E. 2013. The application of a limestone weathering index at churchyards in central Oxford, UK. Applied Geography, 42, 157-164. 
Viles, H.A., 1999. 'Unswept stone, besmeer'd by sluttish time': Air pollution and building stone decay in Oxford, 1790-1960. Environment and History, 2, 359-372.

Whelpdale, D., Summers, P. and Sanhueza, E. 1997. A global overview of atmospheric acid deposition fluxes. Environmental Monitoring and Assessment, 48, 217-247. 


\section{Figures}

A.

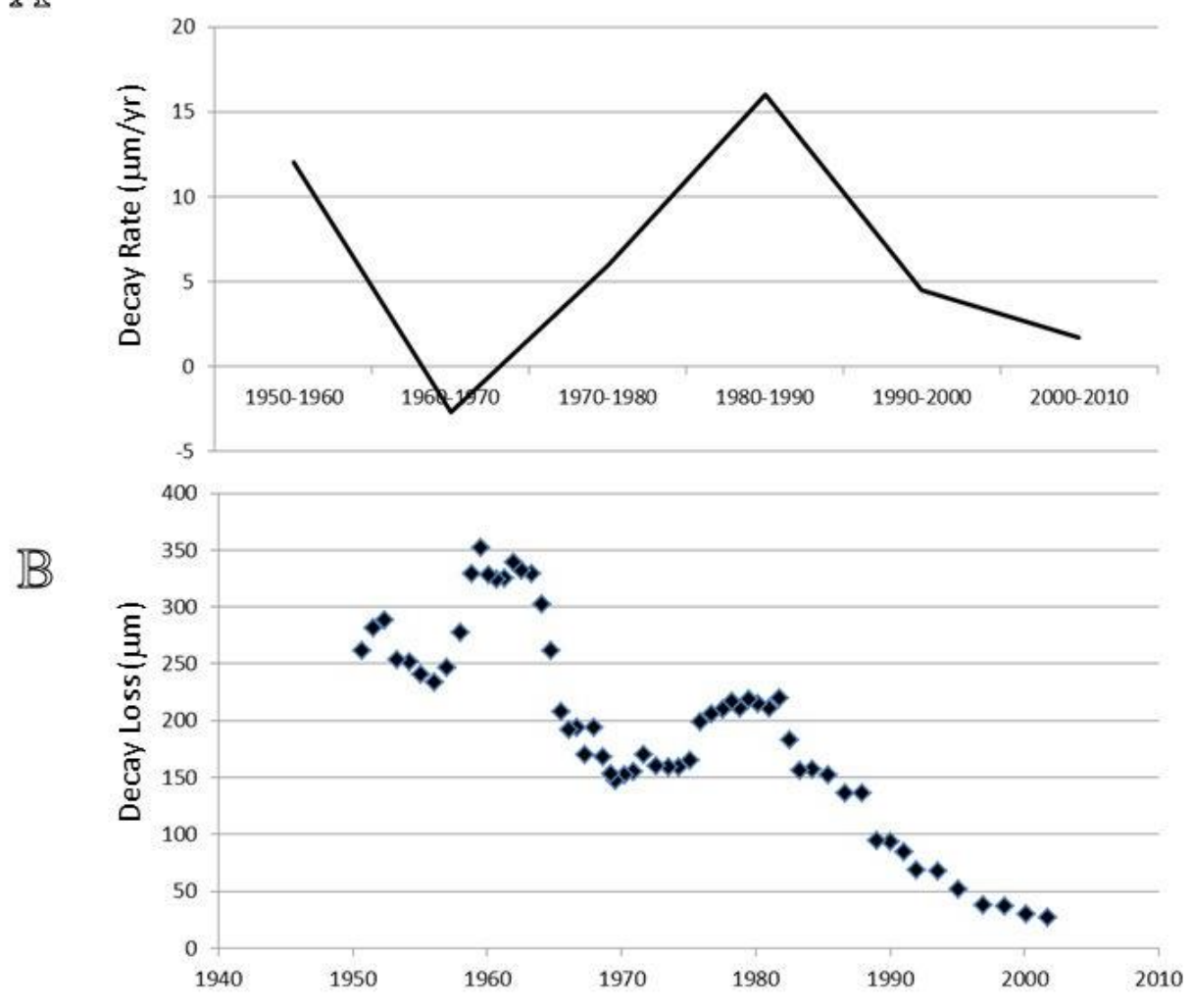

1A- Decay rates calculated using the Integrative Method for decades 1950-1960 to 2000-2010 for Lodge Hill (Selly Oak) Cemetery

1B- 10 year moving average of decay losses for Lodge Hill (Selly Oak) Cemetery between 1950 and 2010

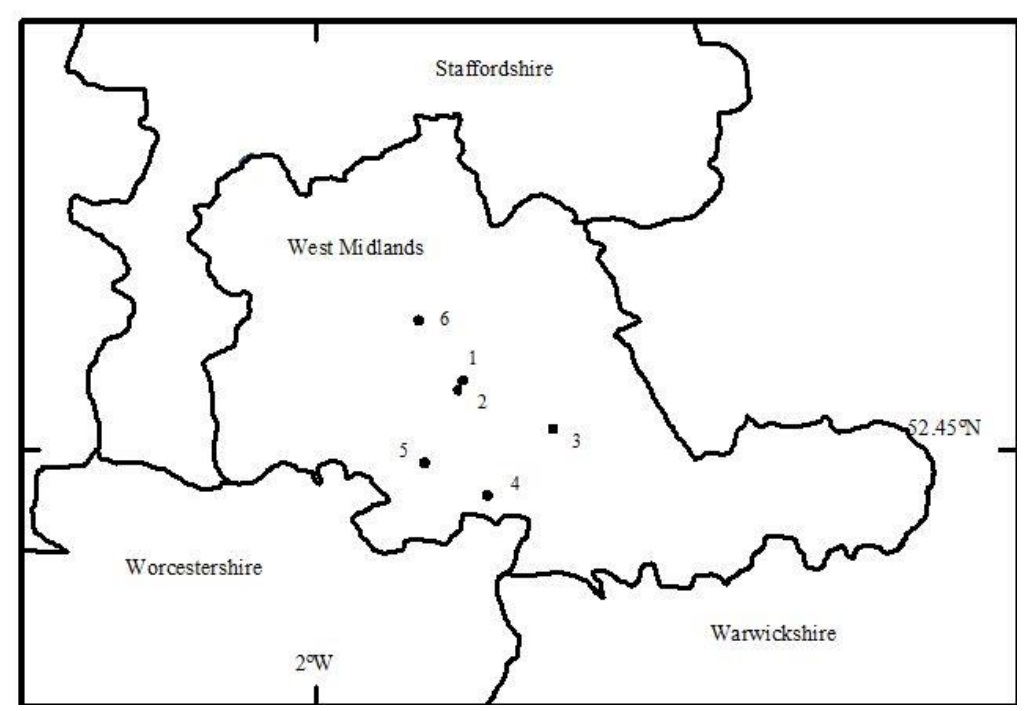




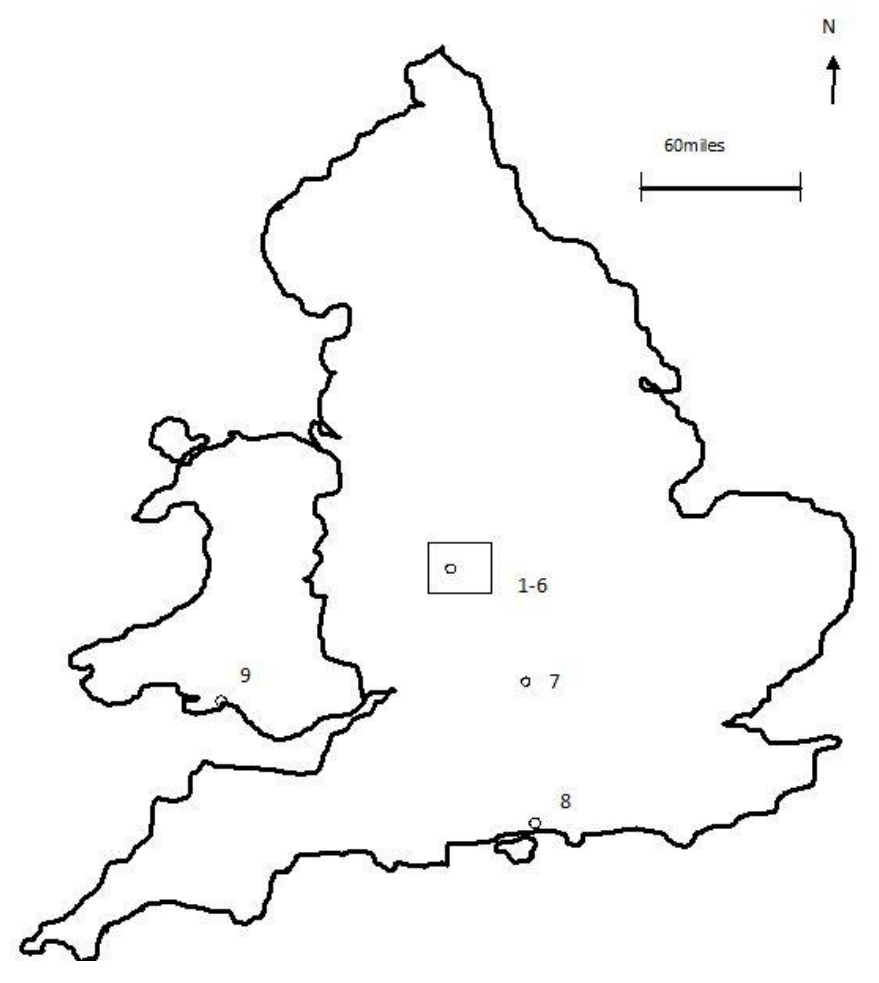

2A and B - Location of cemeteries: A: Birmingham sites 1-6 are 1: Key Hill, 2: Warstone, 3: South Yardley, 4: Kings Heath, 5: Lodge Hill (Selly Oak), 6: West Bromwich, B: site 7: Oxford, site 8: Portsmouth, site 9: Swansea

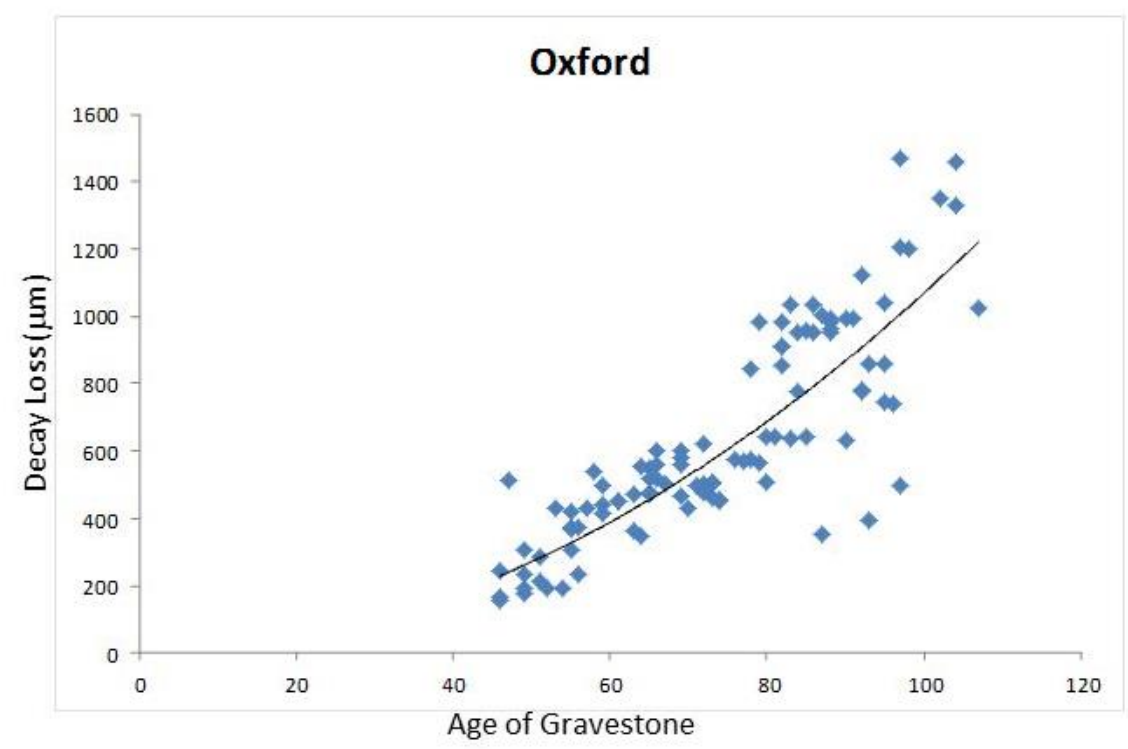

3- Illustration of power relationship between decay loss in microns and age of gravestone for Oxford 


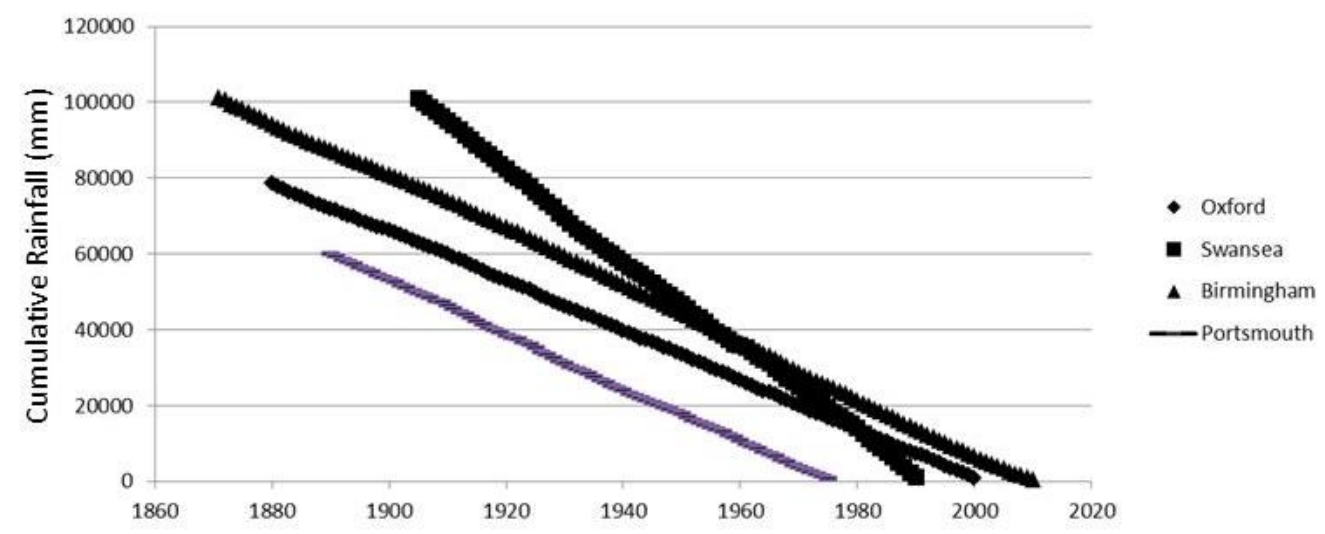

4- Relationship between cumulative rainfall and decay losses for Birmingham (Edgbaston), Oxford, Portsmouth and Swansea

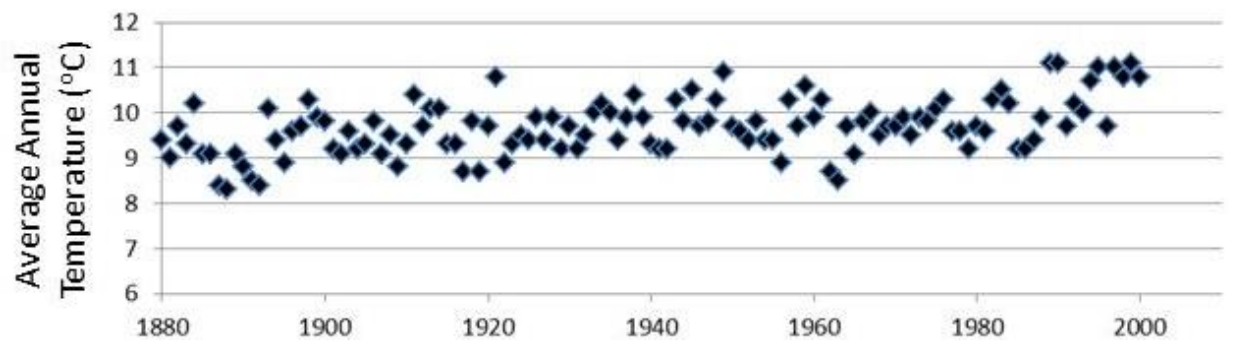

5- Relationship between annual average temperature and date for Oxford

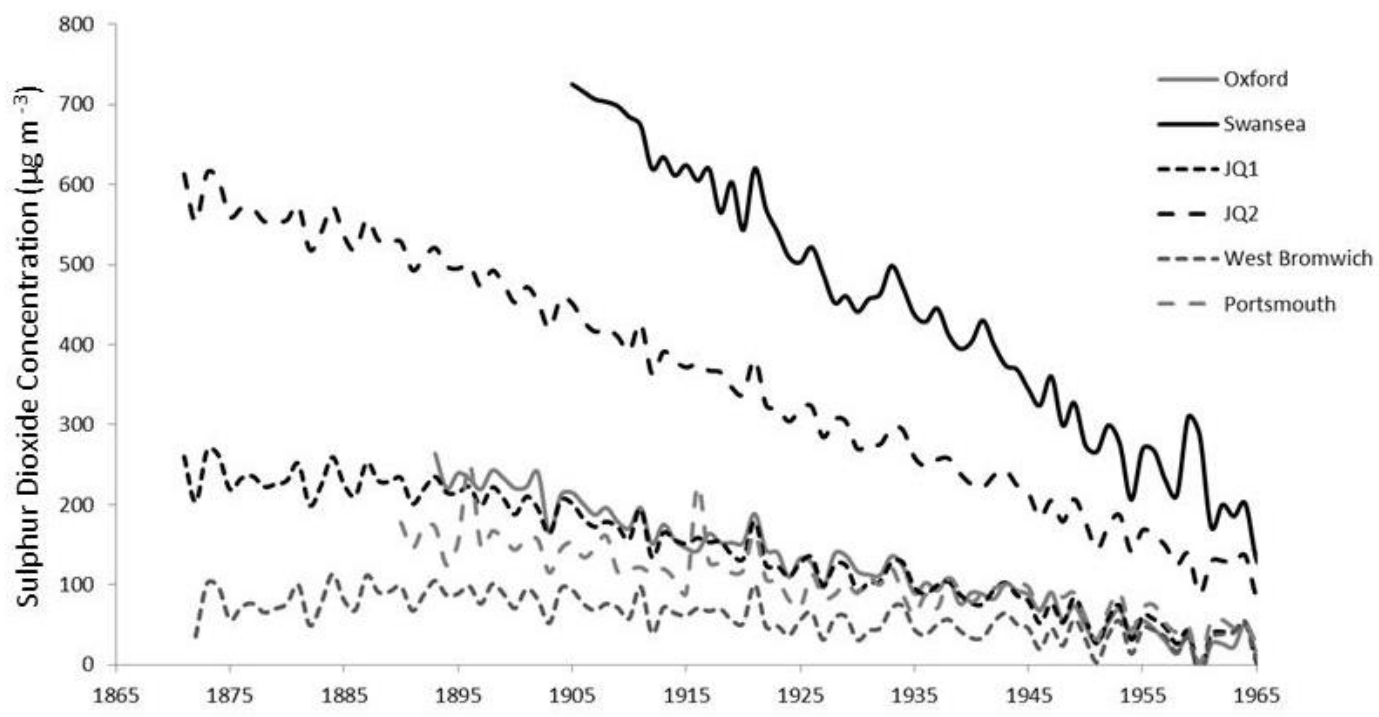

6- Changes in sulphur dioxide concentrations for Oxford, Swansea, Warstone and Key Hill (Birmingham), West Bromwich and Portsmouth up to 1965 


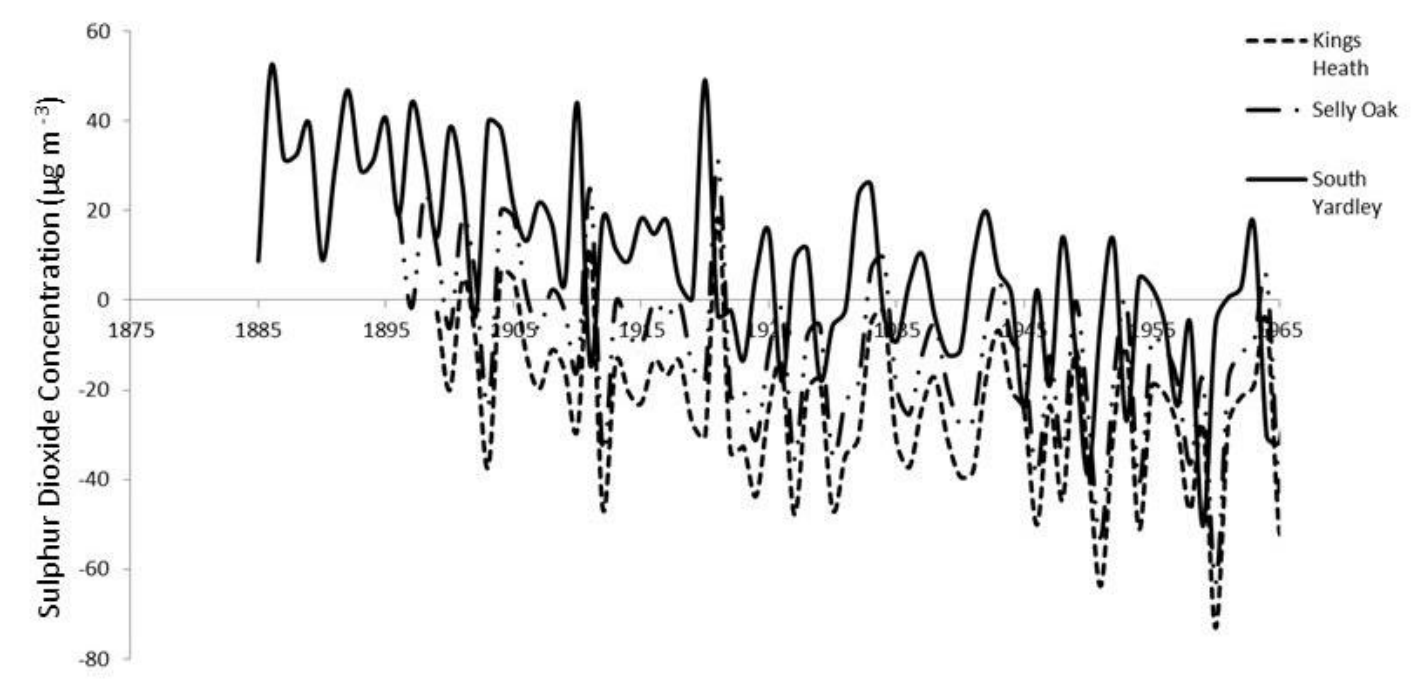

7- Changes in sulphur dioxide concentrations for Kings Heath, Selly Oak and South Yardley up to 1965

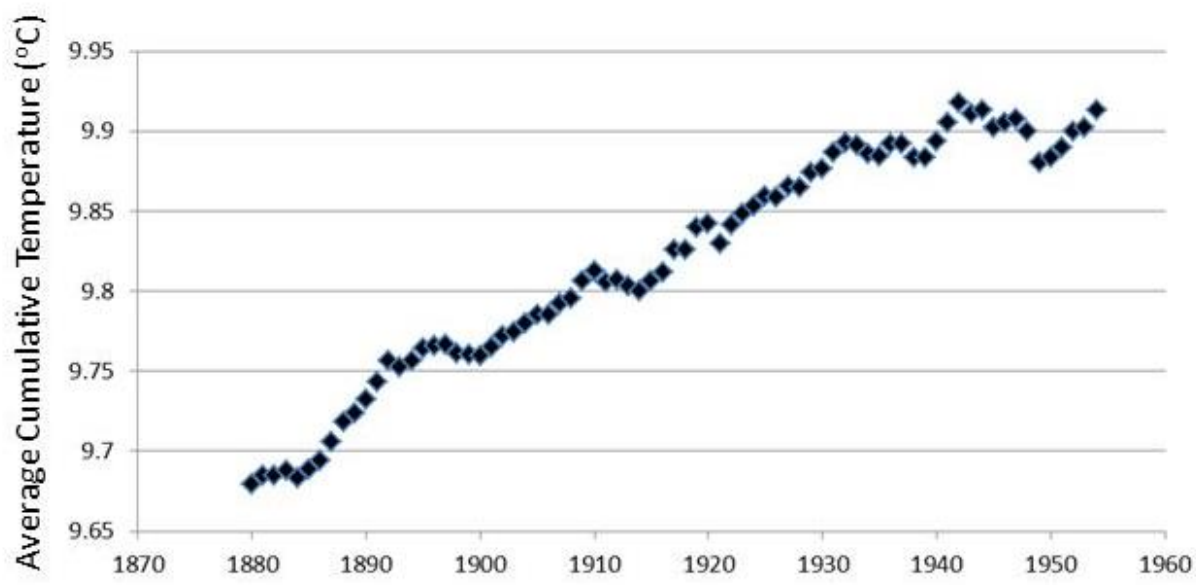

8- Relationship between average cumulative temperature and date for Oxford 


\section{Tables}

\begin{tabular}{|c|c|c|c|c|c|c|c|c|c|c|c|}
\hline 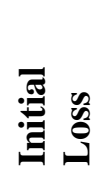 & 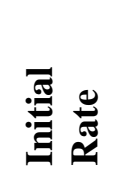 & 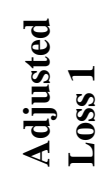 & 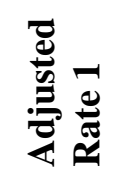 & 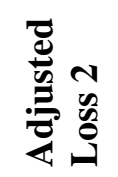 & 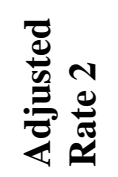 & 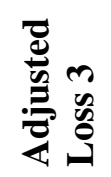 & 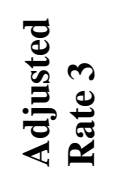 & 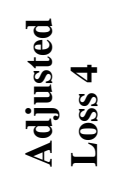 & 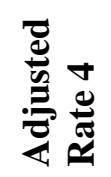 & 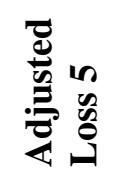 & 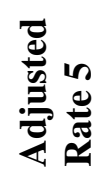 \\
\hline 323 & 26.9 & 313 & 26.1 & 277 & 23.1 & 183 & 15.3 & 106 & 8.8 & 149 & 12 \\
\hline 174 & 10.9 & 164 & 10.3 & 128 & 8 & 34.4 & 2.2 & -43 & -2.7 & & \\
\hline 217 & 16.7 & 207 & 15.9 & 171 & 13.2 & 77.5 & 6 & & & & \\
\hline 140 & 23.3 & 130 & 21.6 & 94 & 16 & & & & & & \\
\hline 45.8 & 5.7 & 35.8 & 4.5 & & & & & & & & \\
\hline
\end{tabular}

Table 1 - Integrative rate calculation of gravestone decay for Selly Oak cemetery for post1950 measurements. Calculated decay losses in microns and calculated decay rates in $\mu$ per year in bold

\begin{tabular}{lllllll}
\hline & $\begin{array}{l}\text { Linear } \\
\text { Regression }\end{array}$ & & \multicolumn{3}{l}{$\begin{array}{l}\text { Power } \\
\text { Function }\end{array}$} \\
\hline & $\mathrm{x}$ & $\mathrm{c}$ & $\mathrm{r}^{2}$ & $\mathrm{a}$ & $\mathrm{b}$ & $\mathrm{r}^{2}$ \\
\hline Oxford & 16.051 & -553.36 & 71 & 0.1168 & 1.9808 & 74 \\
\hline Swansea & 46.573 & -1245.1 & 77 & 0.469 & 1.9376 & 86 \\
\hline Warstone & 16.454 & -432.83 & 57 & 0.2428 & 1.8225 & 77 \\
\hline Key Hill & 23.291 & -492.42 & 69 & 0.1916 & 1.9917 & 80 \\
\hline Portsmouth & 15.866 & -415.84 & 60 & 1.026 & 1.5226 & 76 \\
\hline West & 13.94 & -233.24 & 86 & 2.209 & 1.3076 & 69 \\
Bromwich & & & & & & \\
\hline Kings Heath & 5.4184 & -12.572 & 47 & 2.686 & 1.1441 & 61 \\
\hline Selly Oak & 7.4127 & -73.175 & 52 & 2.6096 & 1.1754 & 73 \\
\hline South & 6.2604 & 42.996 & 38 & 2.2357 & 1.2362 & 70 \\
Yardley & & & & & & \\
\hline
\end{tabular}

Table 2- Comparison of linear regression and power functions used to describe relationship between decay loss (in microns) and age of gravestone 